\title{
Long-lasting insecticidal net source, ownership and use in the context of universal coverage: a household survey in eastern Rwanda
}

Fredrick Kateera ${ }^{1,2^{*}}$, Chantal M. Ingabire ${ }^{1}$, Emmanuel Hakizimana ${ }^{3}$, Alexis Rulisa ${ }^{4}$, Parfait Karinda ${ }^{1}$, Martin P. Grobusch², Leon Mutesa ${ }^{5}$, Michèle van Vugt ${ }^{2}$ and Petra F. Mens ${ }^{2,6}$

\begin{abstract}
Background: Universal long-lasting insecticidal net (LLIN) coverage (ULC) has reduced malaria morbidity and mortality across Africa. Although information is available on bed net use in specific groups, such as pregnant women and children under 5 years, there is paucity of data on their use among the general population. Bed net source, ownership and determinants of use among individuals from households in an eastern Rwanda community 8 months after a ULC were characterized.

Methods: Using household-based, interviewer-administered questionnaires and interviewer-direct observations, data on bed net source, ownership and key determinants of net use, including demographics, socio-economic status indicators, house structure characteristics, as well as of bed net quantity, type and integrity, were collected from 1400 randomly selected households. Univariate and mixed effects logistic regression modelling was done to assess for determinants of bed net use.

Results: A total of 1410 households and 6598 individuals were included in the study. Overall, the proportion of households with at least one net was $92 \%$ while bed net usage was reported among $72 \%$ of household members. Of the households surveyed, a total ownership of 2768 nets was reported, of which about $96 \%$ were reportedly LLINs received from the ULC. By interviewer-physical observation, $88 \%$ of the nets owned were of the LLIN type with the remaining $12 \%$ did not carry any mark to enable type recognition. The odds of bed net use were significantly lower among males and individuals: from households of low socio-economic status, from households with <two bed nets, from households reporting use of $\geq$ two sleeping spaces, and those reporting to have not slept on a bed.

Conclusion: In this study, despite high a bed net coverage, over $25 \%$ of members reported not to have slept under a bed net the night before the survey. Males were particularly less likely to use bed nets even where nets were available. Household socio-economic status, number of bed nets and type and number of sleeping spaces were key determinants of bed net use. To maximize impact of ULC, strategies that target males as well as those that ensure ITN coverage for all, address barriers to feasible and convenient bed net use including covering over all sleeping space types, and provide net hanging supports, are needed.
\end{abstract}

Keywords: Malaria, Households, Long-lasting insecticidal nets, Ownership, Use, Rwanda

\footnotetext{
${ }^{*}$ Correspondence: fkkateera@yahoo.com

${ }^{1}$ Medical Research Centre Division, Rwanda Biomedical Centre, PO

Box 7162, Kigali, Rwanda

Full list of author information is available at the end of the article
} 


\section{Background}

Insecticide-treated bed nets (ITNs) are a cornerstone of malaria control in sub-Saharan Africa [1, 2]. The World Health Organization (WHO) recommends universal access to, and use of long-lasting insecticidal nets (LLINs) for all individuals at risk of malaria so as to optimize ITN effectiveness [3]. ITNs act by placing a physical barrier between the mosquito and humans and through the repellent toxic effects of the ITN-impregnated insecticides. ITNs have been shown to reduce malaria burden at both individual and community level leading to decreased morbidity, mortality and overall transmission potential $[1,4,5]$. With ITNs also shown to be the most cost-effective intervention in reducing malaria transmission [6], universal long-lasting insecticidal net coverage (ULC) has been recommended and is now widely implemented as a key intervention in malaria control efforts [7].

The impact of LLIN scale-up on reducing malaria burden has been observed in Rwanda [8]. With financial support mainly from The Global Fund to Fight AIDS, Tuberculosis and Malaria and the President's Malaria Initiative, Rwanda achieved ULC-defined as a reported household ownership of at least one bed net per two individuals, as early as February 2011 [9]. However, despite the observed initial decline in health facility-recorded malaria cases and deaths following LLIN scale-up in Rwanda, increases in malaria burden continue to be reported $[8,10,11]$. While the resurgence in 2009 was mainly attributed to a reduced effectiveness of LLINs due to delays in provision of new nets at a time when the effectiveness of the previously provided LLINs was waning [10], later resurgence may have been partly associated with the reported deployment of bed nets with sub-optimal concentrations of insecticide [11]. However, although the reasons for the resurgence were not systematically characterized, continued scale-up and use of LLINs is needed if gains made in malaria burden decline in the past are to be sustained [10]. To achieve and maintain ULC, Rwanda adopted the WHO's recommendations for high malaria burden countries of using multiple distribution channels, including free ULCs that are supplemented by continuous LLIN distributions through programmes such as antenatal care (ANC) and immunization services for pregnant women and infants, respectively $[3,9]$.

A key determinant of ITN impact is bed net use, with previous studies showing disparities between bed net ownership and use [12-17]. One such determinant of bed net use is seasonality. While higher net use has been reported more in the rainy season due to the associated high mosquito density, lower net use has been associated with hot dry months due to heat-related discomfort [12-14]. Other previously reported determinants of net use include number of nets owned per household, sex: with women more likely to use nets [15], age [15], head of household $(\mathrm{HoH})$ education levels, disruptive sleeping arrangements [16], and net misuse such as bed nets being used for activities in agriculture and fishing [17]. Hitherto, studies on bed net use have mostly focused on children $<5$ years and pregnant women, two groups preferentially targeted for net coverage in the past because of their high malaria risk. There is limited and inconclusive data on ITN effectiveness under routine field settings after ULC targeting of all age and gender groups. Understanding these household-level bed net use patterns is needed to inform malaria control programmes on how to optimize bed net public health impact. Here, a community-based evaluation of bed net source, ownership and determinants of use was conducted 8 months after ULC.

\section{Methods}

\section{Study area description and malaria risk}

This cross-sectional survey was conducted among a representative sample of households randomly selected from 35 villages of a rural, predominantly agricultural, Ruhuha sector of Bugesera District in the eastern province of Rwanda from November 2014 to January 2015. Rwanda is broadly divided into four malaria ecologic zones based on altitude, climate, level of transmission, and disease vector prevalence [18]. Topographically, malaria transmission is considered meso-endemic in the plain regions of eastern and southern provinces while being epidemicprone in the high plateau and hill settings of northern and western provinces, respectively [18]. Ruhuha sector is a rural agricultural community that is located in the high malaria transmission zone. The main malaria control interventions used in the study area include ULC, indoor residual spraying (IRS) with insecticide and use of artemisinin combination therapy (ACT).

\section{Study population and eligibility criteria}

This study is part of a larger project that aims to use an integrated (biomedical, anthropological, entomological, and economical), community-based approach targeting reduction of malaria transmission at household level [19]. A sample of 1400 households was randomly selected from a sampling frame of 4522 sector households generated 2 months prior to the survey as part of an enumeration exercise conducted while planning for IRS exercise for the sector. To identify the randomly selected households for study inclusion, study team members visited a particular village and identified the households by the named $\mathrm{HoH}$ on the enumeration sheet. This study and the associated follow-up procedures were then introduced to the $\mathrm{HoH}$ or their spouses who were then requested to provide a written informed consent before 
enrolment. Data on household members aged $>6$ months and who had spent the night prior to the survey at the household were collected. A household was defined as any unit headed by a male or female with his/her dependents and/or spouse who shared a cooking pot/common eating-place.

\section{Study questionnaire and variables definitions}

A pre-coded questionnaire, that was largely adapted from the standard malaria indicator survey (MIS) and the demographic health survey (DHS), was administered to the $\mathrm{HoH}$ or their spouse [20]. Data on demographics (age, sex, education level, occupation, and marital status), household socio-economic status (SES) indicators (including ownership of land and animals, main sources of household amenities (including lighting, cooking and drinking water), ownership of items (such as telephone, television, refrigerator, bicycle and radio), house structural features (such as type of material used to construct house wall and floor), malaria prevention knowledge and practices, bed net characteristics (of ownership, source and use), and IRS activity within 12 months prior to survey, were collected. In addition, a spot check was performed to verify bed net number, brand, shape and integrity (having holes or no holes). A bed net was classified as having holes if it had any finger-sized hole or larger. In this study, three degrees of severity of net deterioration including finger size, fist size and head size were assessed for.

\section{Data collection}

Field workers were trained for 10 days on key survey aspects of study objectives, variable data to be collected and question intent. Additionally, classroom role-plays and piloting of questionnaires were conducted, with daily feedback reviews conducted to ensure consistency of translation and appropriateness of the wording in the local language (Kinyarwanda). Although the questionnaire was developed in English and data captured onto an English language electronic format, both the training and data collection exercise were conducted using paper-based questionnaires that were translated into Kinyarwanda. The electronic format questionnaire was developed using Open Data Kit (ODK) Collect set-up [21]. ODK is an open-source suite of tools that include ODK Collect, an android-based mobile client that acts as the interface between the user and the underlying form used to collect data [21]. The collected data were then electronically uploaded onto a central server and later exported into Microsoft Excel 2007 version (Microsoft Corp) for further analysis.

\section{Bed net distribution}

Between January 2012 and December 2014, bed nets were distributed within the study area using multiple channels, including a ULC targeting the general population, mass distribution of bed nets for all children aged $<5$ years, and continuous distribution through ANC and immunization services. Prior to the ULC, community health care workers (CHWs) enumerated each household for type and number of sleeping spaces and number of bed nets available. Among the general population, 5600 LLINs were distributed in May 2012 and an additional 4550 distributed in May 2013 to achieve complete coverage of all sleeping spaces. However, following these two rounds of net distribution, the LLIN brand (Netprotect ${ }^{\circledR}$ ) provided was later confirmed to be impregnated with sub-optimal amounts of the insecticide [11]. This led to a replacement exercise conducted in March 2014 where 10,150 LLINs were distributed to replace the sub-standard LLINs (Mukamana, pers comm). Concurrently, three supplementary distribution campaigns were run in which 3283 LLINs were distributed to cover children aged $<5$ years in 2012, 540 LLINs distributed to pregnant women through the ANC between 2012 and 2014, and 1295 LLINs distributed through the immunization service to cover infants.

\section{Ethical approval}

Study protocols received ethical and scientific approval from the National Health Research Committee (NHRC) and the Rwanda National Ethics Committee (No. 20/ RNEC/2015), Kigali, Rwanda.

\section{Statistical analysis}

Data analysis was performed using STATA version 13.0 (STATA Corp., College Station, TX, USA) software. Descriptive statistics of frequencies, proportions, cross tabulations with crude Pearson's Chi square tests between outcome and dependent variables were performed. The primary outcome was bed net use-defined as a reported history of sleeping under a bed net the night before the survey. Independent covariates reported by other studies as associated with net use, including but not limited to, age, sex, HoH education level at individual level and number of ITNs, number of residents per household and SES levels at household level were analysed individually for an association with bed net use. All variables that showed evidence for a possible association with bed net use $(p$ value $<0.1)$ were then included in the final mixed effect logistic regression model. This model was chosen to ensure adjustment for individual intra-cluster and household inter-cluster correlation. The 
risk of no bed net use under final multivariate model was considered significant for variables with an effect with a $P$ value $\leq 0.05$ based on Wald tests.

\section{Generating household-level socio-economic status (SES) scores}

Measures of household wealth can be reflected by income, consumption or expenditure-related indicator information. To generate household-level SES scores using principal component analysis (PCA) as described elsewhere [22, 23], 17 indicators were used: (1) any household member ownership of television (yes/no), radio (yes/no), bicycle (yes/no), and telephone (yes/ no); (2) HoH ownership of house lived in (yes, no-pay rent, no-use without paying rent); (3) type of sources for: (a) lighting (electricity, kerosene, oil, gas or paraffin lamps, solar, firewood, candles/battery/flash lights, others), (b) cooking (electricity, biogas/LPG/natural gas, paraffin, charcoal, firewood/straw, others), (c) domestic water (private connection to pipeline, public well, borehole, harvested rain water, river, stream, lake, or other surface water, public tap, public tap/standpipe, bottled water, others), and (d) toilet (flash toilet, pit latrine, ventilated improved pit (VIP) latrine, no facility/bush/field); (4) material used to construct: (a) house walls (burnt bricks, cement/concrete blocks, adobe/un-burnt bricks, $\mathrm{mud} /$ poles, others) and (b) house floors (carpet, parquet, polished wood, mosaic or tiles, cement/concrete, bricks, clay/earth, dung/sand); (5) $\mathrm{HoH}$ enrolment into any health insurance (yes/no); (6) $\mathrm{HoH}$ membership into an economic group (yes/no); (7) ability of $\mathrm{HoH}$ to save any money in past 3 months (yes/no); (8) ability of $\mathrm{HoH}$ to pay for medical services (yes/no) and ability of $\mathrm{HoH}$ to pay for medications prescribed (yes/no); and, (9) highest level of $\mathrm{HoH}$ education (none, primary, secondary, tertiary). Other SES indicator variables for whom data was collected but that had a frequency of $<1 \%$ were omitted due to their low ability to differentiate between households. The PCA derived scores were considered as weight (eigenvectors of the correlation matrix) for each variable and the sum of the weights per household considered as the household level SES score. The scores were then ranked in terciles with the highest $33 \%$ of household considered high SES, the lowest $33 \%$ as low SES and the rest as middle SES [23].

\section{Results}

\section{Baseline household characteristics}

Of the pre-selected 1410 households, six were unoccupied as household members were reported to have moved out of the sector, six $\mathrm{HoH}$ did not provide study consent, ten did not have an eligible person to be interviewed, and 23 households could not be identified because the residents did not know the named $\mathrm{HoH}$. For all omitted households, the nearest household in the same village was identified as a replacement.

Data collected covered 1400 households and 6598 individuals of whom the mean $( \pm \mathrm{SD})$ age was 22.9 $( \pm 18.3), 3282$ (53.3 \%) were female, 582 (9.0 \%) were children $<5$ years. The mean $( \pm S D)$ number of household members was $4.7( \pm 1.9)$ (Table 1$)$.

The majority $(70.9 \%)$ of households had permanent (bricks/cement) wall structures whilst the others households had walls made of temporary (mud and poles) materials. Only $7.1 \%$ and $8.9 \%$ of the households had permanent structured walls and ceilings, structures beneath the roof where bed nets are usually hung, respectively (Table 1).

Two types of sleeping space were identified including a raised up platform (bed) and floor-based spaces. The majority (although not quantified in this study) of the floorbased spaces (although not quantified in this study) were fixed and consistently used spaces, where a mattress or other beddings were placed on the floor. The majority (70.3\%) of the households reported using $\geq$ two sleeping places while the commonest type of sleeping space used was a bed (62.9\%) (Table 1). By households SES levels, the proportions of bed net use among individuals of low, middle and high SES households were 56.5, 64.3 and 65.4\%, respectively.

\section{Bed net ownership, source and integrity}

A majority of $91.7 \%$ households reported owning at least one bed net with a total ownership of 2769 nets reported (1.96 nets/HH). Of the total nets, $86.2 \%$ were reported not frequently in use, with commonest reasons for not using these nets including not needed or lack of where to hang them or not easy to use them due to shape and/ or distance between point of hanging and levels of bedding. The majority $(95.6 \%)$ of nets were received through the ULC with the others either purchased $(n=19)$, or received from family members $(n=28)$ or received from the ANC and immunization clinics $(\mathrm{n}=75)$. By on-spot study interviewer observations on net integrity and brand type, $344(12.9 \%)$ of the nets had at least one hole (of any size) while a total of 2281 (87.9\%) nets were identified as LLINs (Tuzanet, Mamanet and PermaNet ${ }^{\circledR}$ ) while the remaining $12.1 \%$ were found not to carry any mark to enable brand/type recognition, respectively. Details of net source, ownership and integrity are reported in Table 2.

\section{Individual net use}

Overall, $72.3 \%$ individuals reported use of a bed net the night before survey with females $(72.9 \%)$ reporting a slightly higher proportion compared to males (71.6 \%). By age group, 5-15 year olds reported a lower net use 
Table 1 Household $(\mathrm{N}=1410)$ socio-demographic and house structural features, Ruhuha sector, Rwanda, 2015

\begin{tabular}{|c|c|c|}
\hline Variable name & Variable groups & Frequency, $\mathrm{n}(\%)$ \\
\hline \multirow[t]{2}{*}{ Sex of head of household $(\mathrm{HoH})$} & Male & $1021(72.4)$ \\
\hline & Female & $389(27.6)$ \\
\hline Age of $\mathrm{HoH}$ in years & Mean ( \pm SD) & $44.7( \pm 14.5)^{\mathrm{a}}$ \\
\hline \multirow[t]{4}{*}{ Highest educational level attained by $\mathrm{HoH}$} & None & $415(29.4)$ \\
\hline & Primary school & $790(56.0)$ \\
\hline & Post primary/vocational & $36(2.6)$ \\
\hline & Secondary or higher & $169(12.0)$ \\
\hline \multirow[t]{5}{*}{ Marital status of $\mathrm{HoH}$} & Never married & $46(3.3)$ \\
\hline & Married & $654(46.4)$ \\
\hline & Living together & $319(22.6)$ \\
\hline & Separated/divorced & $108(7.6)$ \\
\hline & Widowed & $283(20.1)$ \\
\hline Household $(\mathrm{HH})$ member size & Mean ( \pm SD) & $4.69( \pm 1.9)^{\mathrm{a}}$ \\
\hline Proportion of $\mathrm{HoH}$ with no formal education & None & $415(29.4)$ \\
\hline \multirow[t]{3}{*}{ HH socio-economic status (SES) score } & Low & $470(33.4)$ \\
\hline & Middle & $470(33.4)$ \\
\hline & High & $468(33.2)$ \\
\hline \multirow[t]{2}{*}{ Does the HH own the house currently lived in? } & Yes & $1250(88.8)$ \\
\hline & No & $158(11.2)$ \\
\hline \multirow[t]{2}{*}{ Type of sleeping spaces used in $\mathrm{HH}$} & Beds & $1819(62.9)$ \\
\hline & Floor & $1075(37.1)$ \\
\hline Average number sleeping spaces in $\mathrm{HH}$ visited & Mean $( \pm S D)$ & $2.17( \pm 0.9)^{\mathrm{a}}$ \\
\hline \multirow[t]{4}{*}{ Number of sleeping spaces per $\mathrm{HH}$} & 1 & $294(20.9)$ \\
\hline & 2 & $697(49.5)$ \\
\hline & 3 & $339(24.0)$ \\
\hline & $\geq 4$ & $79(5.6)$ \\
\hline Average number of rooms in household visited & Mean $( \pm S D)^{a}$ & $2.96( \pm 1.2)$ \\
\hline \multirow[t]{5}{*}{ Number of rooms in house lived in } & 1 & $141(10.1)$ \\
\hline & 2 & $250(17.7)$ \\
\hline & 3 & $738(52.4)$ \\
\hline & 4 & $175(12.4)$ \\
\hline & $\geq 5$ & $105(7.4)$ \\
\hline \multirow[t]{2}{*}{ Number of windows in the house lived in } & $0-2$ & $419(29.7)$ \\
\hline & $\geq 3$ & $991(70.1)$ \\
\hline Did the house have a ceiling? & Yes & $101(7.1)$ \\
\hline
\end{tabular}

a Standard deviations

$(68.9 \%)$ relative to children $<5$ years $(74.9 \%)$ and persons aged $\geq 16$ years $(73.1 \%)$, respectively (Table 2 ). Notably, net use was much higher for individuals who slept on a bed $(81.6 \%)$ compared to $64.2 \%$ those who reported sleeping on a mattress placed on the floor (Table 2). In $53.9 \%$ of the household, at least one person did not sleep on a permanent bed but used a sleeping place laid on the ground. However, because individual level data on type of sleeping space used night before survey were not collected, it was impossible to directly assess the association between bed net use and type of sleeping space. In total, $13.8 \%$ of the nets were reportedly not in frequent use although owned, with the commonest reasons as reported by interviewees but not verified by study team, for not using a bed net being the discomfort associated the hot season period (38.9\%), infestation with bed bugs that was associated with use of bed nets $(18.3 \%)$, no particular reason $(6.6 \%)$, net being damaged $(2.6 \%)$, and no need to use a bed net as after a recent IRS activity $(2.4 \%)$. 
Table 2 Bed net source, ownership and use, Ruhuha Sector, Rwanda, 2015

\begin{tabular}{|c|c|c|}
\hline Variable & Variable groups & Frequency, n (\%) \\
\hline \multirow[t]{2}{*}{ Bed net ownership per HH } & Number of HHs with at least one bed net & $1292(91.7)$ \\
\hline & Number of HHs without any bed net & $118(8.3)$ \\
\hline \multirow[t]{4}{*}{ Bed net source } & From government through mass LLIN campaigns & $2647(95.6)$ \\
\hline & From government through antenatal care and immunization clinics & $75(2.7)$ \\
\hline & Privately purchased & $19(0.7)$ \\
\hline & Provided for by family/relatives & $28(1.0)$ \\
\hline \multirow{5}{*}{ Number of bed nets ownership per $\mathrm{HH}$} & 1 & $326(23.3)$ \\
\hline & 2 & $595(42.6)$ \\
\hline & 3 & $275(11.7)$ \\
\hline & $\geq 4$ & $96(6.8)$ \\
\hline & No responses & $104(7.4)$ \\
\hline Total number of nets owned in HHs visited & $\mathrm{N}$ & 2768 \\
\hline Number of nets used night before the survey & n (\%) & $2386(86.2)$ \\
\hline Mean number of bed nets per $\mathrm{HH}$ & Mean $( \pm S D)$ & $2.1( \pm 0.3)^{a}$ \\
\hline Mean number of sleeping spaces $(N=6603)$ & Mean $( \pm S D)$ & $2.1( \pm 0.9)^{a}$ \\
\hline Ratio of bed nets per sleeping space & Mean $( \pm S D)$ & $1.0( \pm 0.4)^{a}$ \\
\hline Number of persons who slept under net & n (\%) & $3,525(72.3)$ \\
\hline \multirow[t]{2}{*}{ Number of bed net used by sex } & Female & $1895(72.9)$ \\
\hline & Male & $1630(71.6)$ \\
\hline \multirow{3}{*}{ Number of bed net used by age group } & $<5$ years & $432(74.9)$ \\
\hline & $5-15$ years & $810(68.9)$ \\
\hline & $>15$ years & $3523(73.1)$ \\
\hline \multirow[t]{2}{*}{ Number of bed net used by sleeping space type } & Slept on beds & $1387(81.6)$ \\
\hline & Slept with no beds & $576(64.2)$ \\
\hline \multirow[t]{4}{*}{ Bed net integrity: presence and size of holes } & Number of nets with no hole & $2425(87.7)$ \\
\hline & Number of nets with at least one finger size hole & $200(7.2)$ \\
\hline & Number of nets with at least one hand size hole & $81(2.9)$ \\
\hline & Number of nets with at least one head size hole & $62(2.2)$ \\
\hline
\end{tabular}

a Standard deviations

\section{Determinants of net use}

Based on univariate analysis, a strong relation was found between net use and house structure characteristics. Persons living in houses with walls made of brick/cement blocks had a 2.4-fold higher odds of net use relative to persons living in houses with walls were made of mud and poles. In addition, the number of doors and windows a house had influenced bed net use by univariate analysis. Individuals from houses with $\geq$ two doors and those from houses with $\geq$ three windows had six- and fourfold more odds of bed net use than individuals with $<$ two and <three doors and windows, respectively. Univariate results are shown in Table 3. However, for both number of doors and number of windows variables, this effect did not retain significance after adjusting for all the other determinants in the final model.

By univariate analysis, nets with holes were significantly less used than nets without holes $(\mathrm{OR}=0.26$,
$P=0.001)$. However, this significance was not sustained after adjusting for other variables in the final multivariate model (Table 3 ). Variables, including a reported history of a family member experiencing a febrile illness in the past 3 months, IRS application, bed net age, $\mathrm{HoH}$ education, household size, houses with ceilings or houses having eaves, did not influence net use in this study.

In the final multivariate model, only five of the 13 explanatory variables including sex, household level SES level, type and number of sleeping arrangements and the number of bed nets owned showed significantly effect on bed net use (Table 3). Males showed 0.4 [95\% confidence interval (CI): $0.28-0.64$ ] times lower odds of sleeping under a net compared to females. Also, individuals living in households of middle/high SES showed twofold higher odds of net use compared to those living in household low SES household. 
Table 3 Logistic regression analysis of determinants of bed net use among individuals $(\mathrm{n}=6598)$ from households with $\geq$ one net Ruhuha sector, Rwanda, 2015

\begin{tabular}{|c|c|c|c|}
\hline Variable & $\begin{array}{l}\text { Variable } \\
\text { Sub-group }\end{array}$ & Univariate OR (95\% Cl), P value & Multivariate OR (95\% Cl), P value \\
\hline \multirow[t]{2}{*}{ Sex } & Female (reference) & - & - \\
\hline & Male & $0.57(0.44-0.74),<0.0001$ & $0.42(0.28-0.64),<0.0001$ \\
\hline \multirow[t]{3}{*}{ Age group of all $\mathrm{HH}$ members in years } & $0-5$ years (reference) & - & - \\
\hline & $6-15$ & $0.38(0.23-0.63),<0.0001$ & $0.197(0.01-3.01), 0.243$ \\
\hline & $>15$ & $0.86(0.54-1.36), 0.510$ & $0.35(0.03-4.69), 0.431$ \\
\hline \multirow[t]{3}{*}{ Age group of $\mathrm{HoH}$ in years. } & 18-30 (reference) & - & - \\
\hline & $31-55$ & $0.93(0.42-2.07), 0.852$ & - \\
\hline & $56+$ & $0.36(0.14-0.96), 0.042$ & - \\
\hline Education level of $\mathrm{HoH}$ & Any vs. none (reference) & $2.53(1.29-4.96), 0.007$ & $0.86(0.38-1.94), 0.720$ \\
\hline \multirow[t]{3}{*}{ Household SES score level } & Low (reference) & - & - \\
\hline & Middle & $1.95(0.92-4.12), 0.079$ & $2.26(1.06-4.82),<0.0001$ \\
\hline & Upper & $1.88(0.89-3.97), 0.099$ & $2.92(1.31-6.46),<0.0001$ \\
\hline \multirow[t]{3}{*}{ Number of members per $\mathrm{HH}$} & 1-3 (reference) & - & - \\
\hline & $4-6$ & $0.38(0.19-0.76), 0.006$ & $0.73(0.33-1.62), 0.432$ \\
\hline & $7+$ & $0.68(0.27-1.67), 0.398$ & $1.86(0.59-5.89), 0.291$ \\
\hline Slept on a bed last night? & Yes vs. no (reference) & $5.24(3.15-8.72),<0.0001$ & $3.01(1.79-5.08),<0.0001$ \\
\hline \multirow[t]{4}{*}{ Number of sleeping space used in $\mathrm{HH}$} & 1 (reference) & - & - \\
\hline & 2 & $1.02(0.86-1.22), 0.790$ & $0.34(0.12-0.99), 0.048$ \\
\hline & 3 & $1.32(1.08-1.61), 0.007$ & $0.11(0.03-0.40), 0.001$ \\
\hline & $4+$ & $1.67(1.23-2.27),<0.0001$ & $0.07(0.01-0.49), 0.007$ \\
\hline Does ITN have any holes? & Yes vs. no (reference) & $0.26(0.11-0.58), 0.001$ & $0.53(0.23-1.18), 0.119$ \\
\hline \multirow[t]{3}{*}{ Number of rooms per $\mathrm{HH}$} & 1 (reference) & - & - \\
\hline & 2 & $14.49(3.30-63.64),<0.0001$ & $2.43(0.60-9.84), 0.214$ \\
\hline & $3+$ & $22.91(5.96-88.01),<0.0001$ & $2.14(0.49-9.35), 0.313$ \\
\hline \multirow[t]{3}{*}{ Number of doors per $\mathrm{HH}$} & 1 (reference) & & - \\
\hline & 2 & $5.26(2.28-12.11),<0.0001$ & $2.42(0.84-6.98), 0.102$ \\
\hline & $3+$ & 8.55 (2.15-34.02), 0.002 & $1.22(0.23-6.64), 0.817$ \\
\hline \multirow[t]{4}{*}{ Number of windows per $\mathrm{HH}$} & 1 (reference) & - & - \\
\hline & 2 & $3.44(0.70-16.83), 0.127$ & $3.32(0.82-13.42), 0.092$ \\
\hline & 3 & $10.74(2.41-47.79), 0.002$ & $1.81(0.45-7.28), 0.406$ \\
\hline & $4+$ & $6.74(1.24-36.72), 0.027$ & $1.11(0.19-6.38), 0.908$ \\
\hline \multirow[t]{4}{*}{ Number of bed nets used per $\mathrm{HH}$} & 1 (reference) & - & - \\
\hline & 2 & $7.10(4.08-12.33),<0.0001$ & $4.72(2.08-10.72),<0.0001$ \\
\hline & 3 & $12.18(5.88-25.23),<0.0001$ & $16.83(5.42-52.24),<0.0001$ \\
\hline & $4+$ & $40.32(8.11-200.51),<0.0001$ & $110.15(11.99-1012.17),<0.0001$ \\
\hline
\end{tabular}

Cl confidence interval

Sleeping on a bed was associated with three-fold higher odds of net use (95\% CI: 1.79-5.08) compared to not sleeping on a bed. Although a reported ownership of $\geq$ two ITNs on the night before the survey was associated with higher odds of net use in general, bed net use was also influenced by the number of sleeping places in a house. Persons from households that reported using $\geq$ two sleeping spaces the night before the survey were associated with higher odds of net use compared to household that had only one sleeping space. Multivariate results are shown in Table 3.

\section{Discussion}

This study demonstrated a $92 \%$ household ownership with at least one net and a $72 \%$ bed nets use among 1400 households visited. Particularly among men, and in households of the low SES group with $\geq$ two sleeping places, where individuals reported not sleeping on a bed, 
with a reported ownership of only one bed net, lower odds of net use were observed. Also, higher odds of net use with increasing number of nets in household were observed.

Comparable to the $92 \%$ household bed net ownership in this study, high coverage rates have been reported elsewhere following UCL, including Sierra Leone (87.6\%), Togo (96.7 \%) and Ethiopia (91.0 \%) [24-26]. Similarly as shown in this study, bed net use in these three settings was lower than bed net coverage, varying from $65.0 \%$ in Ethiopia to $68.3 \%$ in Togo and $76.5 \%$ in Sierra Leone. This finding highlights a major need to supplement ULC with appropriate effective strategies that promote bed net use.

As observed in this study, previous studies have shown that females were more likely to use bed nets relative to males [27-29]. A possible reason for the sex disparity in net use could be the traditionally high focus on promoting net use among females through health centres and ANC-based campaigns to target reduction of malaria risk for vulnerable pregnant women. This focus may have spilled over into higher rates of net use among females even in settings of ULC and in spite of the observed lower likelihood of net use amongst men. However, the specific reasons for low rates of net use among men were not explored in this study. Characterizing these reasons is key to identifying implementation gaps and targeting strategies towards promoting net use specifically among men.

In this study, individuals who reported not to have slept on a bed had lower odds of net use compared to those who slept on beds. In one study in Kenya conducted before and after a ULC, lower odds by 0.24 and 0.31 fold decrease among individuals who reported sleeping on the floor compared to those who slept on a bed was observed [30]. In this same study, sleeping on the floor was almost fully associated with not using a net [30]. Possible reasons for lower compliance to bed net use among those not sleeping on a bed range from practical house structural challenges, including difficulty in spreading a net over a sleeping material or a mattress, lack of a suitable structure for net hanging and disruptive sleeping arrangements that complicate ease of bed net use [16, 31]. Although not studied here, it is plausible that bed net use is particularly difficult among those who did not sleep on a bed as the sleeping spaces are generally larger, irregular and much further from the point of net hanging and hence less amenable to feasible bed net use. In this study, $93 \%$ of the houses visited had no ceiling, structures onto which nets are usually hung. It is plausible that lack of a place to hang or a need to improvise, such as by tying a long string from wall to wall onto which a net can be secured and as well as difficulty in securing net around floor-based sleeping arrangements, are some reasons for reduced likelihood of bed net use. Bed net hanging increases likelihood of bed net use [32]. Further characterization of feasibility of bed net hanging and convenience of net use among those who do not sleep on a bed is needed to promote bed net use in this group. .

Households with $\geq$ two sleeping spaces were associated with lower odds of net use. Given the bed net to household ratio of almost 2:1 (2769 bed nets for 1410 households) in the study area, it is likely, although not specifically assessed in this study, that households with more sleeping places did not have enough bed nets to cover each sleeping space. In this study, a progressive increase in odds of net use proportional to number of used nets the night before the survey was observed. Comparable findings to this study have been reported elsewhere. In Ethiopia, a household level net density of >one net per two people was associated with a fivefold (in 2006) and a twofold (in 2007) higher net use when compared to households with net densities of <one net per two persons [32]. In Sierra Leone, a ULC was associated with a $137 \%$ increase in bed net use within 6 months [24]. In Uganda, following a ULC, LLIN availability was the only determinant of bed net use [31]. This is plausible in this study area where there is a discrepancy between mean of household members size (4.7) and mean number of available nets (2.1), which is lower than the target of having one net per two household occupants. Therefore, since a greater intra-household access to an ITN is a strong determinant of net use, efforts to increase access to enough bed nets, particularly in households with many members, is required. To further increase net use among all age and gender sub-groups, net distribution campaigns should target coverage of at least of all sleeping spaces and ideally coverage of two nets per three persons or even one net per person.

Medium and high SES group households were associated with higher odds of bed net use in this study. Similar to findings in this study, higher net use amongst households with higher SES has been reported previously in Uganda [33], and in Ethiopia [34]. A possible reason for this observation may be that individuals from medium and high SES households have better information on access and capacity to buy supplementary LLINs and hence are more likely to use bed nets. Interestingly, associations between household SES and net use have been reported with mixed outcomes. In a smaller, prospective, hospital-based study in Nigeria, household SES did not influence bed net use [35]. In contrast, Auta et al. in a study based on data extracted from a demographic and health survey exercise in Nigeria found higher rates of net use among individuals from the lowest wealth quintile [36]. In the latter study, higher rates of net used was 
associated partly with a higher perception of malaria risk in the poorest settings that may have arisen from more concerted public health campaigns conducted in the area [36]. On the contrary, higher SES group households may have greater access to more nets or more favourable factors that enhance adherence to net use.

The methodology employed and study findings had major strengths. Interviewer-spot checks in assessing bed net ownership, integrity and brand as well as verifying house structural feature characteristics limited potential recall and socio-desirability bias. In addition, both the interview questions used that were adapted from the standardized MIS and DHS tools and the quantitative analysis employed served to optimize study accuracy. This study evaluated for a key outcome of bed net use in a setting of high net coverage and hence provided rich data on the effectiveness of a UCL in a real community setting. The methodology used in this study had some limitations. Firstly, the decision to replace the 35 non-enrolled houses randomly selected households with nearest neighbour households may have had an effect on representativeness of the study findings. This most likely did no affect accuracy of study findings given that the proportion of replaced households was $<2.5 \%$ of total sample size. Secondly, this being a cross-sectional survey, study findings may be confounded by unmeasured factors, not be suitable for drawing causal inferences, and not be appropriate for showing how net ownership and use may vary over time. A possible social desirability bias of over-reporting may also have influenced rates of reported net ownership and use. In addition, the study area has had many bed net campaigns that may have positively influenced knowledge and attitudes on malaria prevention and in particular, led to higher rates of net use. Study findings may not be representative of low malaria endemic settings with low bed net coverage and limited awareness of bed net use. Given that this survey covered a relatively limited area, findings may not be generalizable to the entire country and more so in settings when ULC were not conducted.

\section{Conclusion}

Bed net ownership of $\geq$ one net among households visited and a reported individual use among households members of 92 and $72 \%$ was observed in the study area. This study confirmed that males in general and individuals from households of low SES, with one or more nets, where $\geq$ two sleeping spaces are used, and those who slept on the floor relative to those who used beds, were less likely to use a net. Supplementary to LLIN scale-up campaigns, strategies to promote bed net use, particularly among males and houses with structural features that prevent mosquito entry and those that adapt bed net feasibility towards ease of use in groups such as those who do not sleep on a bed, are needed. Also, further studies on feasibility and cost-effectiveness research of ULC, as well as in-depth anthropological studies characterizing bed net use patterns, including reasons for lower net use among males, perceptions on bed net hanging, net characteristics that may lead to reduced bed net use, such as dirtiness, smells, shape, and colour and challenges of net use among those do not sleep on beds, would provide rich contextual data to inform future strategies aimed at improved net use.

\section{Authors' contributions}

FK conceived the study, supervised the fieldwork, analysed the data and drafted the manuscript. CMI was involved in study conception and study implementation. EH and AL were both involved in developing study tools, training field interviewers and study implementation. MPG provided guidance on the manuscript draft. LM was involved in study implementation and critically reviewed draft manuscript. MvV was involved in study conception and provided input on draft manuscript preparation. PFM prepared data collection tools, provided guidance on data analysis and interpretation and substantially revised the manuscript. All authors read and approved the final manuscript.

\section{Author details}

${ }^{1}$ Medical Research Centre Division, Rwanda Biomedical Centre, PO Box 7162, Kigali, Rwanda. ${ }^{2}$ Division of Internal Medicine, Department of Infectious Diseases, Centre of Tropical Medicine and Travel Medicine, Academic Medical Centre, Meibergdreef 9, 1100 DE Amsterdam, The Netherlands. ${ }^{3}$ Malaria and Other Parasitic Diseases Division, Rwanda Biomedical Centre, Kigali, Rwanda. ${ }^{4}$ Department of Cultural Anthropology and Development Studies and Centre for International Development Issues, Radboud University, 6500 HE Nijmegen, The Netherlands. ${ }^{5}$ College of Medicine and Health Sciences, University of Rwanda, PO Box 3286, Kigali, Rwanda. ${ }^{6}$ Royal Tropical Institute/ Koninklijk Instituut voor de Tropen, KIT Biomedical Research, Meibergdreef 39, 1105 AZ Amsterdam, The Netherlands.

\section{Acknowledgements}

We thank Ruhuha sector households and their members who participated in this study, the area CHWs and the leadership of Ruhuha Health Centre for their partnership. The Netherlands Organization for Scientific Research (NWO-WOTRO) funded this work (Grant: AMC A1050243). Florance Mukamana provided data on bed nets distributed.

\section{Compliance with ethical guidelines}

\section{Competing interests}

The authors declare that they have no competing interests.

Received: 19 June 2015 Accepted: 25 September 2015

Published online: 06 October 2015

\section{References}

1. Lengeler $C$. Insecticide-treated bed nets and curtains for preventing malaria. Cochrane Database Syst Rev. 2004;2:CD000363.

2. Alonso PL, Armstrong JR, Lindsay SW. Malaria, bed nets, and mortality. Lancet. 1991;338:897.

3. WHO. WHO recommendations for achieving universal coverage with long-lasting insecticidal nets in malaria control. World Health Organization, Geneva. 2014. http://www.who.int/malaria/publications/atoz/ who_recommendations_universal_coverage_Ilins.pdf. Accessed 13 April 2015.

4. Hawley WA, Phillips-Howard PA, Kuile FO, Terlouw DJ, Vulule JM, Ombok $M$, et al. Community-wide effects of permethrin-treated bed nets on 
child mortality and malaria morbidity in western Kenya. Am J Trop Med Hyg. 2003;68:121-7.

5. Eisele TP, Steketee RW. African malaria control programs deliver ITNs and achieve what the clinical trials predicted. PLoS Med. 2011:8:e1001088.

6. WHO Global Malaria Programme. A WHO Position statement on ITNs. http://www.ivcc.com/sites/ivcc.mrmdev.co.uk/files/content/itnspospaperfinal.pdf. Accessed 11 April 2015.

7. Teklehaimanot A, Sachs JD, Curtis C. Malaria control needs mass distribution of insecticidal bednets. Lancet. 2007;369:2143-6.

8. Otten M, Aregawi M, Were W, Karema C, Medin A, Bekele W, et al. Initial evidence of reduction of malaria cases and deaths in Rwanda and Ethiopia due to rapid scale-up of malaria prevention and treatment. Malar J. 2009;8:14.

9. President's Malaria Initiative. Rwanda malaria operational plan FY 2014 http://www.pmi.gov/docs/default-source/default-document-library/ malaria-operational-plans/fy14/rwanda_mop_fy 14 .pdf?sfvrsn $=8$. Accessed 23 May 2015.

10. Karema C, Aregawi MW, Rukundo A, Kabayiza A, Mulindahabi M, Fall IS, et al. Trends in malaria cases, hospital admissions and deaths following scale-up of anti-malarial interventions, 2000-2010, Rwanda. Malar J. 2012;11:236.

11. Binagwaho A, Karema C. A call for international accountability-preserving hope amid false protection. Lancet Glob Health. 2015;3:e188-9. doi:10.1016/S2214-109X(15)70014-8

12. Binka FN, Adongo P. Acceptability and use of insecticide impregnated bednets in northern Ghana. Trop Med Int Health. 1997;2:499-507.

13. Thwing J, Hochberg N, Vanden Eng J, Issifi S, Eliades MJ, Minkoulou E, et al. Insecticide-treated net ownership and usage in Niger after a nationwide integrated campaign. Trop Med Int Health. 2008;13:827-34.

14. Korenromp EL, Miller J, Cibulskis RE, Kabir Cham M, Alnwick D, Dye C. Monitoring mosquito net coverage for malaria control in Africa: possession vs. use by children under 5 years. Trop Med Int Health. 2003;8:693-703.

15. Baume CA, Marin MC. Intra-household mosquito net use in Ethiopia, Ghana, Mali, Nigeria, Senegal, and Zambia: are nets being used? Who in the household uses them? Am J Trop Med Hyg. 2007;77:963-71.

16. Alaii JA, Hawley WA, Kolczak MS, ter Kuile FO, Gimnig JE, Vulule JM, et al. Factors affecting use of permethrin-treated bed nets during a randomized controlled trial in western Kenya. Am J Trop Med Hyg. 2003;68:137-41.

17. Ingabire C, Rulisa A, Van Kempen L, Muvunyi C, Koenraadt C, Van Vugt M, et al. Factors impeding the acceptability and use of malaria preventive measures: implications for malaria elimination in eastern Rwanda. Malar J. 2015;14:136.

18. $\mathrm{PMI} / \mathrm{MOH}-\mathrm{Rwanda}$. President's malaria initiative Rwanda malaria operational plan FY. 2015. http://www.pmi.gov/docs/default-source/defaultdocument-library/malaria-operational-plans/fy-15/fy-2015-rwandamalaria-operational-plan.pdf?sfvrsn=3. Accessed 22 Sep 2015.

19. Rulisa S, Kateera F, Bizimana JP, Agaba S, Dukuzumuremyi J, Mens Petra F, et al. Malaria prevalence, spatial clustering and risk factors in a low endemic area of eastern Rwanda: a cross sectional study. PLoS One. 2013;8:e69443. doi:10.1371/journal.pone.0069443.

20. USAID. The DHS program, demographic and health surveys. http://www dhsprogram.com. Accessed 24 May 2015.

21. Raja A, Tridane A, Gaffar A, Lindquist T, Pribadi K. Android and ODK based data collection framework to aid in epidemiological analysis. Online J Public Health Inform. 2014;5:228.

22. Vyas S, Kumaranayake L. Constructing socio-economic status indices: how to use principal components analysis. Health Policy Plan 2006:21:459-68
23. Filmer D, Pritchett LH. Estimating wealth effect without expenditure data or tears: an application to educational enrollments in states of India. Demography. 2001;38:115-32.

24. Bennett A, Smith SJ, Yambasu S, Jambai A, Alemu W, Kabano A, et al. Household possession and use of insecticide-treated mosquito nets in Sierra Leone 6 months after a national mass-distribution campaign. PLoS One. 2012;7:e37927. doi:10.1371/journal.pone.0037927.

25. Stevens ER, Aldridge A, Degbey Y, Pignandi A, Dorkenoo MA, HugelenPadin J. Evaluation of the 2011 long-lasting, insecticide-treated net distribution for universal coverage in Togo. Malar J. 2013;12:162.

26. Baume CA, Reithinger $\mathrm{R}$, Woldehanna $\mathrm{S}$. Factors associated with use and non-use of mosquito nets owned in Oromia and Amhara regional states, Ethiopia. Malar J. 2009;8:264.

27. Wanzira H, Yeka A, Kigozi R, Rubahika D, Nasr S, Sserwanga A, et al. Long lasting insecticide-treated bed net ownership and use among children under 5 years of age following a targeted distribution in central Uganda. Malar J. 2014;13:185

28. Ter Kuile FO, Terlouw DJ, Phillips-Howard PA, Hawley WA, Friedman JF, Kolczak WS, et al. Impact of permethrin-treated bed nets on malaria and all-cause morbidity in young children in an area of intense perennial malaria transmission in western Kenya: cross-sectional survey. Am J Trop Med Hyg. 2003;68:100-7.

29. Garley AE, Ivanovich E, Eckert E, Negroustoueva S, Yazoume Y. Gender differences in the use of insecticide-treated nets after a universal free distribution campaign in Kano State, Nigeria: post-campaign survey results. Malar J. 2013;12:119.

30. Larson PS, Minakawa N, Dida GO, Njenga SM, lonides EL, Wilson ML. Insecticide-treated net use before and after mass distribution in a fishing community along Lake Victoria, Kenya: successes and unavoidable pitfalls. Malar J. 2014;13:466.

31. Iwashita H, Dida G, Futami K, Sonye G, Kaneko S, Horio M, et al. Sleeping arrangement and house structure affect bed net use in villages along Lake Victoria. Malar J. 2010;9:176.

32. Graves PM, Ngondi JM, Hwang J, Getachew A, Gebre T, Mosher AW, et al. Factors associated with mosquito net use by individuals in households owning nets in Ethiopia. Malar J. 2011;10:354.

33. Njau JD, Stephenson R, Menon M, Kachur SP, McFarland DA. Exploring the impact of targeted distribution of free bed nets on households bed net ownership, socio-economic disparities and childhood malaria infection rates: analysis of national malaria survey data from three sub-Saharan Africa countries. Malar J. 2013;12:245

34. Sena LD, Deressa WA, Ali AA. Predictors of long-lasting insecticidetreated bed net ownership and utilization: evidence from communitybased cross-sectional comparative study, Southwest Ethiopia. Malar J. 2013;12:406.

35. Edelu BO, Ikefuna AN, Emodi Jl, Adimora GN. Awareness and use of insecticide-treated bed nets among children attending outpatient clinic at UNTH, Enugu - the need for an effective mobilization process. Afr Health Sci. 2010;10:117-9.

36. Auta A. Demographic factors associated with insecticide treated net use among Nigerian women and children. N Am J Med Sci. 2012:4:40-4.

\section{Submit your next manuscript to BioMed Central and take full advantage of:}

- Convenient online submission

- Thorough peer review

- No space constraints or color figure charges

- Immediate publication on acceptance

- Inclusion in PubMed, CAS, Scopus and Google Scholar

- Research which is freely available for redistribution

Submit your manuscript at

www.biomedcentral.com/submit
C Biomed Central 